\title{
Acupressure versus Pursed Lip Breathing Techniques on Physiological Parameter and Dyspnea Grade among Patients with Chronic Obstructive Pulmonary Disease
}

\author{
Tahani Ali Maharem ${ }^{1}$, Abeer Abd El Rahman Mohamed ${ }^{2}$ \& Hanan Ali Almanzlawi ${ }^{3}$ \\ 1. Clinical instructor in Medical- Surgical Nursing Department, Faculty of Nursing, Alexandria University, Egypt. \\ 2. Assistant Professor in Gerontological Nursing Department, Faculty of Nursing, Alexandria University, Egypt. \\ ${ }^{3 .}$ Lecturer in Medical-Surgical Nursing Department, Faculty of Nursing, Mansoura University, Egypt.
}

\begin{abstract}
Background: chronic obstructive pulmonary disease (COPD) is a leading cause of morbidity and mortality worldwide. Dyspnea has considered the most common health problem among patients with COPD; nonpharmacological management of dyspnea decreases its grade. Aim: to evaluate the effect of acupressure versus pursed lip breathing techniques on physiological parameter and dyspnea grade among patient with COPD. Design: A quasi-experimental design was utilized. Sample: It included 80 adult patients and divided into two groups as a group (1) acupressure group $(\mathrm{n}=40)$ and group (2) pursed lip breathing techniques $(\mathrm{n}=40)$. Setting: the study was conducted at the chest unit at Alexandria main university hospital. Tools: (1) socio-demographic data questionnaire, (2) Modified medical research council scale (MMRC), and (3) physiological parameter. Results: There was a decrease in dyspnea grade post-pursed-lip breathing group more than acupressure group and there was a statistically significant difference between two groups about dyspnea by the end of the 4th week and respiratory rate \& oxygen saturation. Conclusion: Pursed-lip breathing was effective therapy for patients with COPD to improve dyspnea, physiological parameter, and oxygen saturation, while acupressure has a minimal significant effect on dyspnea grade. Recommendation: Prospective study should be designed to determine the stability of the effect of acupressure to control dyspnea.
\end{abstract}

\section{Keywords: Acupressure, Pursed lip breathing techniques, Dyspnea \& Chronic obstructive pulmonary disease.}

\section{Introduction}

Chronic obstructive pulmonary diseases are a leading cause of morbidity and mortality in the United States and around the world. COPD exacerbations (regular worsening of cough, dyspnea, and sputum production) are a major contributor to affect lung function, quality of life, need for urgent care or hospitalization, and increased healthcare costs COPD. Dyspnea is a multifaceted, subjective ailment that can have a major influence on a patient's quality of life (QOL) (Hariyono et al., 2017).

Chronic obstructive pulmonary disease claimed the lives of about 3.2 million people worldwide in 2017, an increase of 17.5 percent from the previous year increase in the number of deaths between 2007 and 2017. It is due to continued exposure of the people to risk factors especially smoking and the aging process (Halpin et al., 2019).

Dyspnea is a key symptom of chronic obstructive lung disease, and its severity and frequency worsen as the disease advanced, resulting considerable impairment that they become isolated, and describing themselves as "surviving" rather than "living" (Dorman et al., 2017).
In the final year of life, patients with severe COPD always feel significant dyspnea. It is quite frequent as the condition progresses, and 90-95 percent of people with chronic obstructive pulmonary disease (COPD) develop that at some point (Belman et al., 2017). Dyspnea is often treated with a variety of pharmacological and non-pharmacological interventions (Bianchi et al., 2017).

In the clinical setting, no pharmaceutical interventions that affect the emotional and/or cognitive experience of dyspnea, such as acupressure and breathing training, may help relieve breathlessness. In traditional Chinese medicine, acupressure is one of the most common therapeutic modalities. It is a supplementary treatment that stimulates acupoints with the fingers and palms while maintaining energy balance (Rocker et al., 2018). Techniques like pursed lips breathing (PLB), which tries to prolong active expiration by constricting the lips, can be used in breathing training. When comparing between spontaneous breathing, and pursed-lip breathing (PLB), it had been proven that to (PLB) reduce respiratory rate and dyspnea with improving lung function as well as improve tidal volume and oxygenation at rest (Edmonds et al., 2015). 
Significance of the study:

Globally, chronic obstructive pulmonary disease (COPD) is a primary cause of illness and mortality. COPD is the third greatest cause of death in the world, accounting for $5 \%$ of all fatalities. It is anticipated that 64 million people worldwide will get COPD by 2030 (Soriano et al., 2017 \& Padilla, 2017).

Chronic obstructive pulmonary disease was shown to be prevalent in high-risk Egyptians at 9.6\%. A higher frequency of grade $2(69 \%)$ and grade $3(17 \%)$ COPD, as well as a lower prevalence of grade $1(3 \%)$ COPD. As a result, raising COPD knowledge in the general public, particularly among high-risk persons, can help with early detection of the condition (Said et al., 2015).

Pursed Lip Breathing (PLB) is an excellent technique that decreases dyspnea in COPD, increases the tolerance of activities, increases oxygen saturation, ventilation and gas exchange (Hariyono et al., 2017). Hence, the researchers conducted the study to evaluate the effect of acupressure versus pursed-lip breathing techniques on physiological parameters and dyspnea grade among patients with COPD.

Aim of the study:

To evaluate the effect of acupressure versus pursed lip breathing techniques on physiological parameter and dyspnea grade among patients with COPD through:

- Applying acupressure technique on physiological parameter and dyspnea grade among patients with COPD.

- Applying pursed lip breathing technique on physiological parameter and dyspnea grade among patients with COPD.

- Evaluate the effect of acupressure versus pursed lip breathing techniques on physiological parameter and dyspnea grade among patients with COPD

\section{Hypothesis}

Adult patients who are pursed lip breathing techniques will have lower physiological parameters and grade of dyspnea than those who not.

\section{Operational definition:}

Physiological parameter refers to heart rate, respiratory rate, and 02 saturation rate

\section{Subjects and Methods: \\ Research design:}

The current study used a quasi-experimental research design to achieve its goal.

Settings:

The present study was conducted at the chest inpatient unit of Alexandria Main University Hospital. The inpatient chest department has a capacity of 40 beds for male patients and twenty-six beds for female patients. The chest department has a lab for pulmonary function tests. These settings were selected due to the high prevalence of patients in the selected settings and also, it serves the biggest region of the population from both rural and urban areas.

Subjects:

A purposive sample of 80 adult COPD patients was chosen using the Epi info7 tool, which was utilised to estimate the sample size using the following parameters:

1.In 2017, the total population of the aforementioned facility was 271 patients.

2.The expected frequency is $90 \%$.

3.Percentage of acceptable mistake $=10 \%$

4.The confidence coefficient is $95 \%$.

5.The sample size is estimated to be 80 patients with COPD.

They were included and assigned randomly and alternatively into two equal groups of 40 adult patients in each group.

Study group (I): We're exposed to acupressure sessions.

Control group (II): We're exposed to Pursed lip breathing sessions.

Inclusions criteria: The patients were selected according to the following criteria:

- Adult patients can communicate.

- Grade C of COPD stages

Data collection tools:

For data gathering, three tools were used:

After reviewing the related literature and research studies (Chou, Huffman 2017, \& Global Initiative for Chronic Obstructive Lung Disease, 2019), the researchers developed

Tool I: Patient's Bio-demographic Characteristics, which included age, sex, educational level, marital status, occupation, residence, and exacerbation risk.

Tool II: Modified Medical Research Council Scale (MMRC):

The Modified Medical Research Council scale (MMRC) was utilised to develop this tool, which was used to determine the severity of dyspnea. (Bhatt, Dransfield, 2013 \& Global Initiative for Chronic Obstructive Lung Disease, 2019)

The MRC Breathlessness Scale

\begin{tabular}{|l|l|}
\hline Grade & Degree of breathlessness related to activities \\
\hline $\mathbf{1}$ & $\begin{array}{l}\text { Not troubled by breathlessness except on } \\
\text { strenuous exercise }\end{array}$ \\
\hline $\mathbf{2}$ & $\begin{array}{l}\text { Short of breath when hurrying on the level or } \\
\text { walking up a slight hill }\end{array}$ \\
\hline $\mathbf{4}$ & $\begin{array}{l}\text { Walks slower than most people on the level, } \\
\text { stops after a mile or so, or stops after 15 } \\
\text { minutes walking at own pace }\end{array}$ \\
\hline $\mathbf{5}$ & $\begin{array}{l}\text { Stops for breath after walking about 100 yds or } \\
\text { after a few minutes on level ground }\end{array}$ \\
\hline
\end{tabular}


Tool III: physiological or clinical parameter List: The researcher created this instrument after examining related literature (Bhatt \& Dransfield, 2013), and it was used to measure heart rate, the rate of respiration and the rate of oxygen saturation.

Validity of the tools:

All tools were subjected to content validity testing by five specialists in the fields of chest diseases and medical-surgical nursing, and required modifications were made as a result.

\section{Tool testing for reliability:}

Cronbach's alpha was used to assess tool reliability. Tool I had a reliability value of 0.900 , Tool II had a reliability coefficient of 0.980 , and Tool III had a reliability coefficient of 0.830 , indicating that all three tools were reliable.

\section{Methods:}

An official letter from the Faculty of Nursing was submitted to the general director of Alexandria Main University Hospital and the Head of the Chest Department of the same hospital prior to the study's conduct to obtain permission to conduct the study after explanation of the study's purpose.

\section{Ethical considerations:}

After a full description of the study's aim, each patient signed a written informed permission form. Each patient's privacy and confidentiality were guaranteed. The patient's right to withdraw from the study at any time was considered.

\section{Pilot Study:}

A pilot study was conducted before the actual study and was done on $10 \%$ of the sample (8 patients to test the feasibility and applicability of different items of the study tools to establish the most practical and comprehensive way of obtaining necessary data. Pilot study excluded from the actual study.

\section{Data collection:}

- Following administrative clearance, data collecting began in September 2017 and lasted for three months, from September to January 2018. Researchers collected data at the previously described location twice a week, from 9 a.m. to 12 p.m.

- The study's implementation was divided into four phases (assessment, planning phase, implementation phase, and evaluation phase).

\section{Assessment Phase:}

The initial assessment was carried out for every patient in both groups, individually after careful listening and documenting his / her history. Initial assessment: was carried out to collect baseline data for both groups using the tool I, and II. Subsequent assessment: was done one month post sessions for both groups to evaluate the effect of the interventions either acupressure or pursed lip breathing on patients' dyspnea grade and physiological parameters.
Planning phase:

- The researchers established the acupressure and pursed-lip breathing therapies goals, priorities, contents, and expected outcomes for the study group patients based on the data acquired during the assessment phase and literature evaluation.

- Goals and expected outcome of the intervention

- The practice of pursed-lip breathing exercise.

- The practice of acupressure sessions

- Decreasing grade of dyspnea

- Furthermore, the researchers obtained specialized training in the field of acupressure at Alexandria University's Faculty of Physical Education.

\section{Implementation phase:}

- In the inpatient chest department, the interventions were undertaken and applied individually for each patient, as well as discussions and demonstration methods. Patients were also encouraged to bring a member of their family to the event.

- Patients in the acupressure group were asked to repeat the acupressure and PLB techniques until the researcher were satisfied that they had mastered them.

- Acupressure involves massaging critical areas along the body's meridians, known as acupoints, in a clockwise circular motion at six acupoints (LU1, LU7, LU9, LI 4, LI11, and K 3), as depicted in, to stimulate the flow of energy and correct any imbalances. Acupressure session repeated 3 times /week.
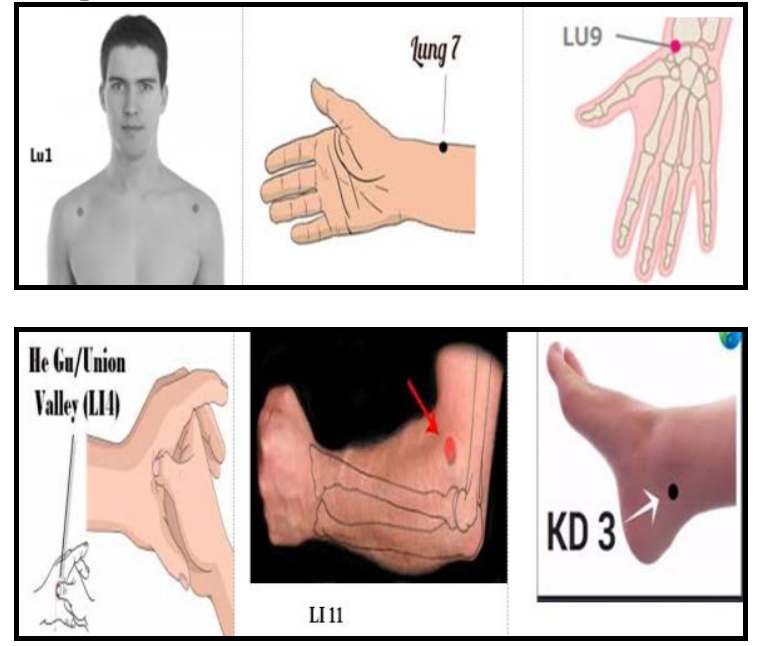

Figure No (1) Acupressure points used in this study (Lee \& Frazier, 2011)

For pursed lip breathing group:

- Patients were instructed to practice pursed-lip breathing PLB techniques until the researcher was satisfied that they had mastered the technique.

- Pursed lip breathing_PLB session repeated 3 times /day for 5-10 breath cycle for 3days per week for one month. 
Evaluation phase:

- After the study, every patient in the study group was re-evaluated four weeks to determine the effectiveness of interventions on dyspnea.

- The comparison was done between the two groups to identify the effectiveness of the acupressure versus pursed lip breathing on dyspnea grade and physiological parameters.

Statistical analysis and data processing

After the data was collected, it was transferred into specifically designed formats that could be fed into a computer. Statistical Package for Social Sciences (SPSS) was used to handle and analyses the data ver.18).

Descriptive statistics:

The mean, median, and standard deviation are terms that are used to describe and summaries a quantitative value. Quantitative variables are described and summarized using counts (numbers) and percentages from the total.

Statistical analysis:

Cronbach's Alpha is a test of reliability. It was used to assess the trustworthiness of all tools. It has a maximum value of $(=1.0)$ and a minimum accepted value of $(=0.7)$; below this level, the instrument is unreliable. The Mann-Whitney U test for quantitative variables and chi-square, Monte Carlo tests for qualitative factors were used to compare the two groups. All of the results were interpreted at a $5 \%$ level of significance (P-value is a statistically significant if $\mathrm{P} \leq 0.05$ ).

\section{Result}

Table (1): Frequency distribution of patients with COPD of both study groups according to demographic characteristics

\begin{tabular}{|c|c|c|c|c|c|c|c|c|}
\hline \multirow[t]{2}{*}{ Items } & \multicolumn{2}{|c|}{$\begin{array}{c}\text { Acupressure Group } \\
1(n=40)\end{array}$} & \multicolumn{2}{|c|}{$\begin{array}{c}\text { PLB Group } \\
2(n=40)\end{array}$} & \multicolumn{2}{|c|}{ Total $(n=80)$} & \multirow[t]{2}{*}{$\mathrm{X} 2$} & \multirow{2}{*}{$\mathbf{P}$} \\
\hline & No. & $\%$ & No. & $\%$ & No. & $\%$ & & \\
\hline \multicolumn{7}{|l|}{ Sex } & \multirow[b]{3}{*}{1.037} & \multirow{3}{*}{$\mathrm{P}=.000$} \\
\hline Male & 38 & $95 \%$ & 40 & $100 \%$ & 78 & $97.5 \%$ & & \\
\hline Female & 2 & $5 \%$ & 0 & $0 \%$ & 2 & $2.5 \%$ & & \\
\hline \multicolumn{7}{|c|}{ Educational level } & \multirow{4}{*}{1.068} & \multirow{4}{*}{$\mathrm{P}=1.456$} \\
\hline Illiterate & 16 & $40 \%$ & 18 & $45 \%$ & 34 & $42.5 \%$ & & \\
\hline Read \&write & 22 & $55 \%$ & 22 & $55 \%$ & 44 & $55 \%$ & & \\
\hline Primary school & 2 & $5 \%$ & 0 & $0 \%$ & 2 & $2.5 \%$ & & \\
\hline \multicolumn{7}{|l|}{ Occupation } & \multirow{3}{*}{1.028} & \multirow[t]{3}{*}{$\mathrm{P}=563$} \\
\hline Housewife & 2 & $5 \%$ & 0 & 0 & 40 & $100 \%$ & & \\
\hline Manual work & 38 & $95 \%$ & 40 & $100 \%$ & 40 & $100 \%$ & & \\
\hline
\end{tabular}

Table (2): Frequency distribution of patients with COPD of in both study groups according to exacerbation risks

\begin{tabular}{|c|c|c|c|c|c|c|}
\hline \multirow{3}{*}{ Items } & \multicolumn{4}{|c|}{ Exacerbation risks } & \multirow{3}{*}{ Total } & \multirow{3}{*}{$\begin{array}{c}\text { Significance } \\
\text { Test }\end{array}$} \\
\hline & \multicolumn{2}{|c|}{ 1-2 times } & \multicolumn{2}{|c|}{ More than2 } & & \\
\hline & No & $\%$ & No & $\%$ & & \\
\hline Acupressure Group1 & 4 & $10.0 \%$ & 36 & $90.0 \%$ & $40(100 \%)$ & \\
\hline Pursed lip breathing Group 2 & 2 & $5.0 \%$ & 38 & $95.0 \%$ & $40(100 \%)$ & $X 2=0.364$ \\
\hline Total & 6 & $7.5 \%$ & 74 & $92.5 \%$ & $80(100 \%)$ & $\mathrm{P}=0.000$ \\
\hline
\end{tabular}

Table (3): Mean values of Pre and post-physiological parameters of the acupressure group.

\begin{tabular}{|c|c|c|c|}
\hline Heart rate & $\begin{array}{c}\text { Acupressure group } \\
(n=40) \text { Mean+SD }\end{array}$ & T-test & $\mathbf{P}$ \\
\hline Pre HR & $92.00 \pm 9.45$ & \multirow{2}{*}{-3.193} & \multirow{2}{*}{0.000} \\
\hline Post HR & $96.57 \pm 10.59$ & & \\
\hline \multicolumn{4}{|l|}{ Respiratory rate } \\
\hline Pre RR & $29.90 \pm 4.98$ & \multirow{2}{*}{-3.984} & \multirow{2}{*}{0.001} \\
\hline Post RR & $32.65 \pm 4.97$ & & \\
\hline \multicolumn{4}{|l|}{ So2 oxygen saturation rate } \\
\hline Pre $\underline{\mathrm{So} 2}$ & $94.60 \pm 2.49$ & \multirow{2}{*}{1.033} & \multirow{2}{*}{0.316} \\
\hline Post So2 & $95.30 \pm 2.48$ & & \\
\hline
\end{tabular}

HR: heart rate RR: respiratory rate So2: oxygen saturation rate 
Table (4): Mean values pre/post of the physiological parameter of the pursed-lip group

\begin{tabular}{|l|c|c|c|}
\hline \multicolumn{1}{|c|}{ Physiological parameter } & PLB group $(\mathbf{n = 4 0})$ Mean+SD & T-test & P \\
\hline Pre HR & $99.60 \pm 7.85$ & \multirow{2}{*}{4.076} & \multirow{2}{*}{.001} \\
\hline Post HR & $87.60 \pm 6.94$ & \multirow{2}{*}{14.385} & \multirow{2}{*}{.000} \\
\hline Pre RR & $32.45 \pm 2.417$ & \\
\hline Post RR & $25.60 \pm 2.15$ & \multirow{2}{*}{$9.835-$} & \multirow{2}{*}{.000} \\
\hline Pre Paso2 & $90.65 \pm 2.519$ & $95.25 \pm 1.66$ & \\
\hline Post Paso2 & &
\end{tabular}

$H R$ : heart rate RR: respiratory rate So2: oxygen saturation rate

Table (5): Mean values of physiological parameter pre and post of the two studied groups

\begin{tabular}{|l|c|c|c|c|}
\hline \multicolumn{1}{|c|}{ Items } & $\begin{array}{c}\text { Acupressure group (n=40) } \\
\text { Mean+SD }\end{array}$ & $\begin{array}{c}\text { PLB group }(\mathbf{n}=\mathbf{4 0}) \\
\text { Mean+SD }\end{array}$ & T-test & P \\
\hline Pre Physiological parameter & $92.00 \pm 8.40$ & $98.00 \pm 7.58$ & 47.68 & .000 \\
\hline HR & $29.90 \pm 4.90$ & $32.32 \pm 2.40$ & 26.53 & .000 \\
\hline RR & $94.60 \pm 2.47$ & $90.42 \pm 2.36$ & 166.2 & .000 \\
\hline Pao2 & \multicolumn{5}{|c|}{} \\
\hline Post Physiological parameter & $95.55 \pm 10.59$ & $88.26 \pm 6.98$ & 39.28 & .000 \\
\hline HR & $31.65 \pm 4.96$ & $25.42 \pm 2.16$ & 27.76 & .000 \\
\hline RR & $94.30 \pm 2.40$ & $94.26 \pm 1.48$ & 170.5 & .000 \\
\hline Pao2 &
\end{tabular}

HR: heart rate RR: respiratory rate So2: oxygen saturation rate

Table (6): Frequency distribution of patients with COPD of both study groups according to Dyspnea grade

\begin{tabular}{|l|c|c|c|c|}
\hline \multirow{2}{*}{ Group } & \multicolumn{4}{|c|}{ Dyspnea grade } \\
\cline { 2 - 5 } & \multicolumn{2}{|c|}{ Dyspnea grade 2 } & \multicolumn{2}{c|}{ Dyspnea grade 3 } \\
\cline { 2 - 5 } & No & $\mathbf{\%}$ & No & $\mathbf{\%}$ \\
\hline After acupressure & 6 & $15 \%$ & 34 & $85 \%$ \\
\hline After PLB & 40 & $100 \%$ & 0 & $0 \%$ \\
\hline
\end{tabular}

Table (1): Revealed that more than three quarters $(97 \%)$ of patients were males, distributed as $95 \%$ in the acupressure group patients and $100 \%$ in the PLB group patients. The difference was highly statistically significant $\left(\mathrm{X}^{2}=1.037, \mathrm{P} .000=\right)$.

Concerning the level of education, it was observed that about $(55 \%)$ half of both study group patients were read and write, with no statistically significant difference $(p=1.456)$. Regarding patients' occupation, it is obvious that the majority of patients (70\% and $85 \%$ ) had manual work in acupressure and PLB groups respectively, with no statistically significant difference. $\mathrm{X}^{2}=1.028, \mathrm{P}=563$ )

Table (2): Showed that concerning exacerbation risks, the table showed that the majority $(90.0 \%$ and $92.5 \%$ ) of studied patients in acupressure and pursed lip breathing groups had exacerbation risks more than 2 times. The difference was highly statistically significant $\left(\mathrm{X}^{2}=0.364, \mathrm{P}=0.000\right)$.

Table (3): Represented that there is no change in the mean value of each heart rate and respiratory rate and oxygen saturation post acupressure sessions.

Table (4): Revealed that there was a decrease in the mean value of each of heart rate and respiratory rate $(87.60 \pm 6.94)(25.60 \pm 2.15)$ respectively post pursed lib breathing and increase in mean oxygen saturation rate $(95.25 \pm 1.66)$ the difference for each of values of $\mathrm{HR}, \mathrm{RR}$ and pao2 post-PLB was were highly statistical significant with $\mathrm{p}=(0.000)$

Table (5): Showed that there was a decrease postPLB in mean heart rate $(88.26 \pm 6.98)$ and respiratory rate $(25.42 \pm 2.16)$ and an increase in mean $\mathrm{Pao} 2$ $(94.26 \pm 1.48)$ in the pursed-lip group more than the acupressure group. Highly statistically significant differences were found between the two groups pre/post interventions regarding mean values of $\mathrm{HR}$, $\mathrm{RR}$, and Paso2 with $\mathrm{P}=0.000$.

Table (6): Illustrated that $85 \%$ of patients post acupressure group intervention had dyspnea grade 3 , on the other hand, all of the patients $(100 \%)$ post-PLB group intervention had dyspnea grade 2 .

\section{Discussion}

Chronic obstructive pulmonary disease (COPD) is the world's third cause of death. COPD, on the other hand, is a diverse group of disorders with a variety of causes, pathogenic mechanisms, and physiological effects. It's a preventable and treatable disease defined by chronic respiratory symptoms and restricted 
airflow caused by airway and/or alveolar abnormalities, which are frequently induced by considerable exposure to noxious particles or gases (Mirza et al., 2018).

Chronic obstructive pulmonary disease (COPD) is a major public health concern around the world. Dyspnea, a key symptom of COPD, it is a major contributor to the disease's symptoms of impairment and anxiety. Dyspnea is commonly treated with a combination of pharmacological and nonpharmacological approaches. Acupressure is a non-invasive manual treatment that includes manipulating the skin and soft tissues with the fingertips rather than needles on acupoints, and is one of the major Traditional Chinese Medicine (TCM) approaches. Patients with chronic obstructive pulmonary disease (COPD) typically adopt a ventilatory approach known as pursed lips breathing (PLB). Pursed lips breathing as a ventilatory method that patients with chronic obstructive pulmonary disease (COPD) frequently use to relieve dyspnea?. As it found to increase gas exchange and decrease dyspnea (Mirza et al., 2018).

The result of the current study revealed that the majority of the patients were males: This is in contrast to (Global Initiative for Chronic Obstructive Lung Disease, 2016), who said that COPD affects men and women almost equally. Al Ghobain et al., (2011) observed that more than two-thirds of males were twice as afflicted as roughly one-third of women. It's possible as the high male gender ratio due to smoking.

The study's findings revealed that half of both study groups' patients could read and write. This conclusion aligned with National Clinical Guideline Centre, (2018), which stated that poor educational level is one of the risk factors for COPD among nonsmokers. According to Prescott et al., (1999) \& NizankowskaMogilnicka et al. (2017) who emphasis that COPD is more common in people with a poor socioeconomic situation and a low degree of education.

The majority of patients in this study had manual labour, which was confirmed by Van et al. (2018), who found that exposure to vapour, gas, dust, and fumes VGDF during work is are related to elevated risk of COPD.

The majority of both groups had exacerbation risk more than twice a year, according to the findings of the current study. These findings match with Peter et al. (2017) finding, who claimed that more than ten percent of patients without an exacerbation history became frequent exacerbates.

The current study found that post-pursed-lip breathing; there was a decrease in mean heart rate and respiratory rate, as well as an increase in mean oxygen saturation rate. The difference between the two groups in terms of mean values of $\mathrm{HR}, \mathrm{RR}$, and $\mathrm{PasO} 2$ were highly statistically significant with $(\mathrm{p}=0.0001)(0.000)$. This proves the beneficial effects of pursed-lip breathing.
This finding is consistent with Garzón (2017), who found that PLB caused significant alterations in HR, RR, and $\mathrm{SpO} 2$, but had no effect on BP.

Results of the current study highlighted that the majority of post acupressure group had dyspnea grade 3 on the other hand about all of the post-PLP group had dyspnea grade 2 this is following Garzón, (2017) finding who reported that PLB decreases RR and increase in SpO2 and the use of PLB relief dyspnea while Marciniuk, (2019) stated that the benefits of pursed-lip breathing in the therapy of dyspnea in among the individual patient with advanced COPD, which are supported by data. In this study where there is a decrease in grade of dyspnea post-PLB due to training and practice of PLB as reported by patients. From the researchers' point of view, this is attributed to the importance of PLB intervention and indicates the success of PLB intervention than acupressure intervention which used to decrease the grade of dyspnea among patient with COPD

This result is consistent with the research conducted by Sade et al., (2020) in which they found in their study titled "Efficacy of Pulmonary Exercises in Chronic Obstructive Pulmonary Disease" as the breathing strategies including pursed lip breathing, and diaphragmatic breathing both had a significant effect on improving dyspnea and oxygen saturation.

Also, the result of this study is supported by the study done by Sachdeva et al., (2018) about "Effectiveness of Pursed Lip Breathing Versus Mouth Mask on Dyspnea and Functional Capacity in Acute Exacerbation of Chronic Obstructive Pulmonary Disease" and proved that pursed lip breathing showed significantly higher improvement in relieving dyspnea. Similary, the study conducted by Maind et al., (2015) to compare the effect of pursed lip breathing and mouth taping on dyspnea, reported that PLB was effective in improving the response to posttest dyspnea status and vital parameters

\section{Conclusion:}

The current study's findings led to the conclusion that patients who receive pursed-lip breathing group training and demonstration their physiological parameter had improved and decrease dyspnea grade than acupressure group.

\section{Recommendation:}

The following suggestions are made in light of the current study's findings:

- The importance of effective demonstration and redemonstration of pursed lip breathing to decrease the grade of dyspnea.

- Future research includes replication of the current study on a large group. 
References

- Al Ghobain, M., Al-Hajjaj, M.S., \& Wali, S.O. (2011): Prevalence of chronic obstructive pulmonary disease among smokers attending primary healthcare clinics in Saudi Arabia. Ann Saudi Med; 31:129-33

- Belman, M.J., Botnick, W.C., \& Shin, J.W. (2017): Inhaled bronchodilators reduce dynamic hyperinflation during exercise in patients with chronic obstructive pulmonary disease. Am J Respir Crit Care Med; 153:967-75

- Bhatt, S.P., \& Dransfield, M.T. (2013): Chronic obstructive pulmonary disease and cardiovascular disease. Transl Res; 162(4): 237-51.

- Bianchi, R., Gigliotti, F., Romagnoli, I., Lanini, B., Castellani, C., \& Grazzini, M. (2017): Chest wall kinematics and breathlessness during pursedlip breathing in patients with COPD. Chest; 125(2):459-65.

- Chou, R., \& Huffman, L.H. (2017): Guideline for the Evaluation and Management of Low Back Pain Evidence Review, American Pain Society.

- Marciniuk, A. (2019): Canadian Thoracic Society COPD Committee Dyspnea Expert Working Group Managing Dyspnea in Patients with Advanced Chronic Obstructive Pulmonary Disease: A Canadian Thoracic Society Clinical Practice GuidelineCanadian Respiratory Journal.Volume 18, Issue 2, Pages 69.

- De, M.M., \& Padilla, J. (2017): Global Initiative for Chronic Obstructive Lung Disease (GOLD)2017: La visión desde alat. Archivos de bronconeumología:Organo oficial de la Sociedad Española de Neumologíay Cirugía Torácica SEPAR y la Asociación Latinoamericana de Tórax (ALAT), 53 (3): 87-8.

- Dorman, S., Byrne, A., \& Edwards, A. (2017): Which measurement scales should we use to measure breathlessness in palliative Palliat Med; 21(3):177-9.

- Edmonds, P., Karlsen, S., Khan, S., \& Addington-Hall, J. (2015): A comparison of the palliative care needs of patients dying from chronic respiratory diseases and lung cancer. Pall Med; 15:287-95.

- Garzón, L.V. (2017): Reactivation of the parasympathetic System with pursed lips after physical exercise.

- Global Initiative for Chronic Obstructive Lung Disease (GOLD). (2019): Global strategy for the diagnosis, management, and prevention of chronic obstructive pulmonary disease.

- Halpin, D.M., Celli, B.R., Criner, G.J., Frith, P., Varela, L., Salvi, S. \& Aisanov, Z. (2019): It is time for the world to take COPD seriously: A statement from the GOLD board of directors. European Respiratory Journal, 54: 190091.

- Hariyono, R., Santoso, S., Arsa, P. \& Rozi, F. (2017): The Influence of Pursed Lip Breathing on Dyspnea, Oxygen Saturation and Activity Tolerance on COPD Patient: Systematic Review. In 8 th International Nursing Conference on Education, Practice and Research Development in Nursing.

- Lee, E., \& Frazier, S. (2011): The efficacy of acupressure for symptom management: a systematic review, Journal of pain and symptom management, 42(4), $589-603$.

- Maciejewski, M. (2020): Quasi-Experimental design. Biostatistics \& Epidemiology; 4 (1): 38-47.

- Maind, G., Nagarwala, R., Retharekar, S., Gondane, S., Bedekar, N., Shyam A. \& Sancheti, P. (2015): Comparison between effect of pursed lip breathing and mouth taping on dyspnoea: A cross sectional study, International Journal of Current Research and Review, 7 (16), 17.

- Mirza, S., Clay, R.D., Koslow, M.A. \& Scanlon, P.D. (2018): COPD guidelines: A review of the GOLD report, In Mayo Clinic Proceedings (Vol. 93, No. 10, pp. 1488-502).

- National Clinical Guideline Centre. (2018): Chronic obstructive pulmonary disease: management of chronic obstructive pulmonary disease in adults in primary and secondary care. www.nice.org.uk/guidance/cg101/resources/gu idance-chronic-obstructive-pulmonary-disease-pdf.

- Nizankowska-Mogilnicka, F., Mejza, A.S. \& Buist, S. (2017): Prevalence of COPD and tobacco smoking in Malopolska region-results from the BOLD study in Poland Pol Arch Med Wewn, 117 (9), 402-10.

- Peter, M.A., Kay, T., Daniel, D., Robert, A., Achim, M., Norbert, M., \& Antonio, A. (2017): Determinants of exacerbation risk in patients with COPD in the TIOSPIR study-3405-3391

- Prescott, P., Lange, J., \& Vestbo, A. (2018): Socioeconomic status, lung function and admission to hospital for COPD: results from the Copenhagen City Heart Study Eur Respir J, 13 (5). 1109-1114.

- Rocker, G., Horton, R., Currow, D., Goodridge, D., Young, J., \& Booth, S. (2018): Palliation of dyspnoea in advanced COPD: Revisiting a role for opioids. Thorax; 64:910-5.

- Sachdeva, S., Pawaria, S. \& Kalra, S. (2018): Effectiveness of Pursed Lip Breathing Versus Mouth Mask on Dyspnea and Functional Capacity in Acute Exacerbation of Chronic Obstructive Pulmonary Disease. International Journal of Health Sciences \& Research, 94 (8): 9.

- Sadei, S., Irintas , E., Inanir, M., Çekmece, Ç. \& Basyig, A. (2020): Efficacy of Pulmonary Exercises 
in Chronic Obstructive Pulmonary Disease. Kocaeli Üniversitesi Sa glık Bilimleri Dergisi, 6 (1): 39-44.

- Said, A.F., Ewis, A.A., Omran, A.A., Magdy, M.E. \& Saleeb, M.F. (2015): Prevalence and predictors of chronic obstructive pulmonary disease among high-risk Egyptians. Egyptian Journal of Bronchology, 9 (1): 27.

- Soriano, J.B., Abajobir, A.A., Abate, K.H., Abera, S.F., Agrawal, A., Ahmed, M.B. \& Alam, N. (2017): Global, regional, and national deaths, prevalence, disability-adjusted life years, and years lived with disability for chronic obstructive pulmonary disease and asthma, 1990- 2015: A systematic analysis for the Global Burden of Disease Study 2015. The Lancet Respiratory Medicine, 5 (9): 691-706.

- Van, H.F., Omvlee, L., Brand, T., \& FringsDresen, M.H. (2018): Perceived barriers and facilitators in the assessment of occupational diseases. Occup. Med. 